\title{
UMA ABORDAGEM ETNOGRÁFICA DO ENSINO PROFISSIONALIZANTE ${ }^{1}$
}

\author{
Antônio de Salvo Carriço ${ }^{2}$
}

\section{Introdução}

A questão da necessidade de se impulsionar o parque industrial e a capacidade produtiva do Brasil vem de longa data. Podemos observar nos anos de 1930, por exemplo, todo um esforço, já bastante estudado, para fazer do país um país urbano e industrial, esforço ao qual estavam atreladas concepções de desenvolvimento, de nação, de economia, de mercado. O surgimento do SENAI, em 1942, se insere nesse contexto onde Estado e indústrias se organizavam para conceber e por em prática maneiras de se prover as condições necessárias para estes processos. Criado sobretudo para atender a uma necessidade que se fazia notar, a falta de uma mão-de-obra qualificada a trabalhar nas indústrias de base, o SENAI viu, desde então, mais de 45 milhões de pessoas passarem por algum dos vários cursos oferecidos.

O ensino profissionalizante, inclusive através de instituições especializadas, portanto, está longe de ser novidade nas pautas seja de governantes, seja de burgueses ou empresários, como quer que os identifiquemos. Recentemente, no entanto, o tema vem ganhando bastante destaque na mídia e pudemos acompanhar o lançamento do PRONATEC, um dos principais programas do governo atual, embora, como de costume, ofuscado no noticiário por denúncias de corrupção de todo tipo.

Se a preocupação com a formação profissional povoa há décadas as atividades de importantes atores sociais, não é surpresa que intelectuais tenham se dedicado ao tema com afinco. Brejon Moysés, por exemplo, lista os prejuízos decorrentes de uma falta de mão-de-obra capaz de suprir as demandas da atividade industrial: menor produção, qualidade inferior dos produtos, retardamento do desenvolvimento. Deve ser projeto de governo, segundo o autor, "planejar a preparação de mão-de-obra, racionalizar seu emprego e evitar desperdícios do potencial de habilidades e capacidades de nossa população" (1961: 60).

A lógica é simples: a atividade industrial no país aumenta (ou se deseja aumentar), mas o número de trabalhadores aptos a realizar os serviços requeridos pelas

\footnotetext{
1 Este artigo se baseia no trabalho apresentado no GT "Antropologia do trabalho e memória dos trabalhadores", na IX Reunião de Antropologia do Mercosul, em Curitiba, coordenado por Carina Balladares (UBA), Juliana Cavilha (UFRGS) e Marta Regina Cioccari (UFRJ).

${ }^{2}$ Universidade Federal do Rio de Janeiro, Brasil.
} 
empresas não acompanha o ritmo. É preciso, portanto, investir na formação desse profissional. É vantajoso para a indústria, que, além de ver suprida uma demanda por mão-de-obra, terceiriza todo o longo, árduo e custoso processo de transformação de uma pessoa qualquer em um trabalhador de determinada área. É bom também para o trabalhador, que tem no ensino profissionalizante as chaves para uma rápida inserção no mercado de trabalho, além de encontrar na escola tudo o que necessita para "aprender uma profissão" e trilhar seu futuro.

Esta relação estabelece uma mediação entre dois pólos: a "indústria", ou o "mercado de trabalho", e o "trabalhador", ou as pessoas em geral. Todo o esforço político e intelectual deve ser direcionado no sentido de encontrar maneiras de prover as melhores condições possíveis para que esta corrente não seja rompida e possa seguir seu fluxo "normal".

\section{Etnografia}

Com esta nova tentativa de revigorar a qualificação profissional, é de se esperar que o tema se torne objeto frequente de uma série de pesquisas das mais variadas disciplinas, mesmo porque abre uma enorme e rica agenda de pesquisa. É nesse sentido, portanto, que este trabalho propõe discutir a questão da qualificação profissional desde uma abordagem especificamente etnográfica, isto é, refletir de que maneiras podemos produzir questões sobre o ensino profissionalizante a partir de etnografias (e que tipo de questões podemos esperar) e, por outro lado, pensar nas experiências apresentadas de modo a discutir a própria prática etnográfica. Para isso, parto da experiência que resultou na minha dissertação de mestrado, baseada em um curso de qualificação do SENAI, na área de panificação, bem como de algumas inquietações experimentadas durante os processos da investigação e da escrita.

Esqueçamos por um instante que o propósito do ensino profissionalizante seja o de suprir uma demanda por uma mão-de-obra especializada. Ignoremos também qualquer dever que tenhamos como intelectuais de pensar meios para aperfeiçoar esse diálogo entre trabalhadores e indústria. Como é o cotidiano de um curso de qualificação? Quais os processos e dinâmicas que ele engendra e como estes são sentidos pelos indivíduos que lhe dão corpo? Trata-se, neste artigo, de trazer à tona certos aspectos que constituem este ambiente da qualificação profissional para refletir acerca das potencialidades e contribuições que estudos de caráter etnográfico podem 
proporcionar, bem como suas condições de produção.

Iniciarei pela questão da etnografia. Coloco como pano de fundo uma questão ao mesmo tempo vaga e complexa, embora aparentemente um tanto quanto ingênua: o que é etnografia? Muito além de uma definição ou de um exame que esgote todos os sentidos adquiridos por este conceito ao longo da história da antropologia, tarefas que extrapolam as possibilidades deste artigo $^{3}$, proponho apenas que se reflita (uma vez mais) sobre as condições de produção de nossos trabalhos. O que diferencia, afinal, um trabalho etnográfico de outras formas de empreender e estruturar (textualmente, inclusive) uma pesquisa sobre determinado tema?

São questões como essa que, em épocas distintas, parecem ter levado pesquisadoras como Florence Weber (2009) e Hortense Powdermaker (1966) a refletir sobre suas pesquisas tendo como foco uma retomada minuciosa de todo o processo da constituição de um campo até a conclusão das obras escritas. Um dos vários aspectos interessantes nas reflexões de ambas as autoras é que, para refletirem sobre suas produções, elas realizam um grande investimento auto-referido, trazendo sua atuação, seus sentimentos, medos, falhas, culpas e decisões como fator central em toda análise. Pesquisadoras e obras dialogam de maneiras que, longe de culminarem em visões simplistas e deterministas de uma parte ou de outra, permitem elaborações bastante produtivas sobre o que é antropologia e o que significa fazer etnografia.

Poderíamos ir além e admitir que, mais que uma discussão apenas metodológica, estaríamos diante de análises antropológicas propriamente ditas, tais como as das obras originais a que se referem? A leitura de Stranger and Friend permite uma compreensão bastante rica das variadas camadas de significado que constituem as tensas relações raciais no Mississipi dos anos 30, por exemplo, bem como as reflexões de Weber sobre sua posição e as múltiplas apropriações de sua presença ao mesmo tempo como emigrada que retorna e pesquisadora/socióloga/estagiária etc. conduzem ao desemaranhar de toda uma rede de sociabilidade constitutiva da região estudada.

A questão pode ser estendida: seria possível, em qualquer etnografia, pensar separadamente questões de método (incluindo aí técnicas de pesquisa e toda a trajetória do pesquisador em campo) e de análise? Afinal, e este é meu ponto aqui, não são técnicas como longas entrevista ou mesmo a observação participante o que realmente

\footnotetext{
${ }^{3}$ Algo mais próximo pode ser encontrado em Stocking (1983), que percorre os significados assumidos pela idéia de trabalho de campo na formação do antropólogo ao longo da história da disciplina, com ênfase em uma contextualização dos postulados de Malinowski.
} 
marca a etnografia enquanto conhecimento, isto é, não se trata simplesmente de uma maneira melhor ou mais apurada (ou pior e menos apurada, para os críticos) de se entender uma realidade ou de se explicar uma série de processos. Se seguirmos a fundo a idéia exposta por Weber (2009) de que todo o processo de participação em diferentes cenas sociais a que se submete o etnógrafo teria um papel central e ativo no conjunto do estudo - e ignorá-lo seria, portanto, extremamente nocivo -, podemos afirmar que o que realmente marca a etnografia (ou pelo menos o que eu gostaria de enfatizar aqui) é que, em relação a outras propostas, ela é totalmente estruturada em função da interação entre o pesquisador e seu objeto: desde a construção de "dados" até sua objetificação textual, é um conhecimento situado, constituído por essas interações, por um lado, ao mesmo tempo em que constitutivo dessas interações. Enquanto outras metodologias podem encarar tais aspectos como condicionantes ou fatores externos à realidade estudada, uma etnografia os traz para o centro de suas preocupações intelectuais. É este, a meu ver, o fator fundamental que não pode ser perdido de vista aqui e que deve ser levado a sério.

\section{Retomada da dissertação}

Deste modo, o que significaria abordar o ensino profissionalizante por meio de etnografias? Há, claro, várias respostas possíveis, vários caminhos que se apresentam de acordo com os interesses, habilidades, oportunidades e relações que o etnógrafo constrói. Essa é uma área extremamente abrangente e que abre um leque muito amplo de possibilidades. Apresentarei aqui a minha experiência, resumidamente, procurando me apropriar dela para dar prosseguimento à discussão proposta.

Minha entrada em campo se deu basicamente como aluno de um curso de qualificação de padeiros, em uma unidade do SENAI no Rio de Janeiro. Após uma série de dificuldades em estabelecer contatos produtivos com o trabalho na indústria de alimentos - um processo importante, mas sobre o qual não me aprofundarei aqui ${ }^{4}$-, matriculei-me finalmente nesse curso, onde integrei uma turma de 8 alunos que freqüentaram as aulas durante os 6 meses de duração, de segunda a sexta pela manhã.

\footnotetext{
${ }^{4} \mathrm{O}$ estudo do trabalho costuma apresentar algumas dificuldades de acesso a pesquisas de disciplinas como a antropologia, baseadas na imersão idealizada de uma etnografia. Essa delicada situação não impediu que vários pesquisadores abordassem o tema, ainda que sem uma conjuntura ideal. De uma maneira ou de outra, aplicando questionários, recorrendo a sindicatos, buscando o trabalhador fora de seu local de trabalho ou mesmo tratando de aspectos em princípio periféricos de seus contextos, cada uma dessas pesquisas experimentou de maneiras distintas as fronteiras temáticas e metodológicas da antropologia. Longe de ser um impeditivo completo, as dificuldades impostas pelos aspectos constitutivos da atividade industrial se mostraram fundamentais para o desenvolvimento e a consolidação da disciplina
} 
A idéia de realizar uma etnografia de um curso de qualificação de mão-de-obra do SENAI resultou de um esforço em conciliar, de alguma forma, os interesses da produção e da pesquisa, que se mostravam refratários e dificultavam minha inserção em campo. Para evitar novas recusas, não me apresentei para algum funcionário como antropólogo, solicitando permissão para realizar minha pesquisa. Pelo contrário, me matriculei no curso como um aluno qualquer, pagando as mensalidades e me sujeitando aos direitos e deveres do cliente-aluno, como nos denominam formalmente. Evidentemente, não escondi de ninguém meus interesses: com o início das aulas, não fiz nenhum alarde, mas me apresentei de maneira sincera quando perguntado.

O curso é dividido em aulas teóricas e aulas práticas. De um lado, aulas como fabricação de pães salgados, pães doces, rústicos e finos, realizadas na oficina, onde os alunos botam a mão na massa, literalmente, e experimentam a produção que realizarão em padarias, indústrias ou produções caseiras - são as chamadas aulas práticas; de outro, aulas de matemática, comunicação, ingredientes e boas práticas de fabricação, ministradas no conforto de uma sala de aula climatizada, alunos sentados em cadeiras razoavelmente confortáveis, de onde são instigados a resolver contas e problemas matemáticos e anotar o que o professor dita ou tenta explicar a respeito de uma série de aspectos da produção de pães, de características da farinha aos processos enzimáticos e de fermentação. Era esse, basicamente, o ambiente do qual eu pude fazer parte e com o qual eu trabalhei para concretizar minha dissertação. Um ambiente, pode-se dizer, "escolar".

\section{Ensino e trabalho}

Tratar-se-ia sobretudo, deste modo, de uma etnografia em uma escola. Como, no entanto, falar sobre o trabalho na indústria alimentícia, meu interesse original de pesquisa, nesse contexto? Como fica a questão do trabalho quando o que o pesquisador tem diante de si é o oposto, isto é, como e em que sentido podemos partir de minhas interações em sala de aula, na oficina e intervalos para falar sobre "trabalho"?

Simoni Guedes aborda essa questão em sua tese, na medida em que aponta que o ensino profissionalizante apresenta uma conjunção peculiar da recorrente oposição teoria e prática: é um espaço onde se pretende uma inserção na prática da produção que se dá fora da prática do mercado de trabalho (Guedes, 1997). Também Bourdieu (2001)

na medida em que forçaram novos questionamentos e novas maneiras de se enxergar velhas questões. 
chama atenção para o afastamento fundamental produzido por instituições de ensino em relação ao "mundo", afastamento este que marca de modo importante suas dinâmicas internas. Este é, portanto, um cenário que nos deixa no mínimo com receios de estabelecer uma passagem, equivalência ou comparação apressada entre educação e trabalho.

É certo, por um lado, que não se trata de uma distinção absoluta entre teoria e prática, ensino e trabalho. Por outro lado, essa é uma relação que deve ser vista com mais cuidado, pois seus termos assumem significados distintos nesse diálogo. Com efeito, esse afastamento em relação à prática do trabalho não implica simplesmente em uma procura pela teoria, a formação "escolar". Embora a busca pela prática se dê no âmbito da teoria, se relacionada ao dia-a-dia do mundo "lá fora", dentro do curso o que se vê é uma transformação desta relação a partir da organização curricular proposta. A percepção do aluno a respeito de teoria e prática se baseia na distinção sala de aula $\mathrm{x}$ prática da oficina. Trata-se, portanto, de duas transformações dessa relação. Por um lado, uma dialética entre teoria e prática que rege as atividades dentro da instituição; toda essa dinâmica, por sua vez, assume a forma de teoria quando posta em relação com o mundo do trabalho, "a vida lá fora". São os estatutos de diferentes trajetórias de formação que estão em questão aqui, quando a noção de qualificação - aliada a uma formação escolar - e sua contrapartida - o trabalhador que se torna o não-qualificado passam a dialogar.

Ensinar teoria, ou melhor, produzir como indispensável um conhecimento teórico, é um dos principais processos em curso na trajetória que faz de uma pessoa ou um padeiro comum um padeiro qualificado. Não se pode dissociar, no entanto, os termos da equação: teoria e prática, ensino e trabalho só são compreendidos em meio a essas complexas significações, que assumem em diálogos constantes.

Falar de trabalho ou mesmo de trabalhadores nesse caso requer uma atenção especial a essas dinâmicas. Mas em que sentido, afinal, trazer para o centro da construção analítica a presença do pesquisador e suas interações com o campo pode promover olhares produtivos?

A possibilidade de deixar-me afetar em campo (Favret-Saada, 1990) é, claro, um dos principais fatores no que diz respeito à aprendizagem do ofício. Se é evidente que não é preciso aprender a fazer pão para estudar o ensino da profissão de padeiro, inserirse nesse processo permite não apenas um ganho pessoal, lúdico até, mas também sentir uma série de agências que estruturam a prática. Lidar com tempos de fermentação, 
aprender a tocar e sentir a massa, são processos cuja compreensão depende de uma efetiva participação, no sentido forte da palavra. Para o padeiro, tal qual o etnógrafo, aprender a fazer pão requer que ele se insira em todo um contexto de percepções onde sua relação com as exigências da massa e da produção é trabalhada a todo momento (Carriço, 2011). A reconstituição da experiência na forma de texto é o complemento desse processo de afetação, que expõe ao leitor e ao próprio pesquisador uma série de processos importantes justamente em suas sutilezas.

Ao mesmo tempo, construir a pesquisa a partir dessa condição significou enfatizar aspectos importantes que constituem o cotidiano do ensino profissionalizante. Em primeiro lugar, me permitiu trabalhar com toda uma estrutura temporal e narrativa promovida pela organização curricular e por características específicas da produção de pães (a saber, as sucessivas fermentações que a massa pede ${ }^{5}$ ). Trata-se de toda uma condução do tempo que alterna períodos de esforço intenso com tempos aparentemente ociosos; que mistura conteúdos previstos pela instituição e trocas de brincadeiras, anedotas e piadas sobre diversos temas.

Trabalhar com esse eixo temporal permite tornar produtivo o afastamento que Bourdieu já mencionava e que se apresenta como uma dificuldade ou uma armadilha em relação ao tema do trabalho, isto é, o "tempo livre e liberado das urgências do mundo que torna possível uma relação livre e liberada com tais urgências e com o próprio mundo" (Bourdieu, 2001: 9).

Deste modo é possível, por exemplo, abordar o humor que pontua as aulas não como um acessório supérfluo ou que faz parte de uma "sociabilidade", simplesmente, mas como fator importante para a formação de um profissional qualificado, para a formação de uma crença na qualificação como valor desejável. Pois é assim que acidentes de trabalho, por exemplo, se constroem enquanto conteúdo programático: a partir de anedotas, "historinhas" contadas por professores e alunos e marcadas por risos e zombarias. Da mesma forma, os episódios citados a seguir, onde as chamadas boas práticas de fabricação não foram seguidas, produzem reações indignadas, enojadas, incentivam mais episódios do mesmo nível e dão corpo, afinal, à higiene como marcador distintivo do padeiro qualificado.

\footnotetext{
${ }^{5}$ Ao contrário do que seria esperado em uma produção efetiva, onde o tempo de fermentação de uma massa corresponde ao tempo de preparo de outra, os alunos produzem em geral apenas uma fornada, $o$ que imprime intervalos bastante longos ao andamento da produção nas aulas.
} 
"E isso por que você tá ali na frente dela vendo, né? Imagina o que não fazem quando não tem ninguém vendo?", provoca Beto. É o mote para mais histórias de André:

"E quando o funcionário acha que vai prejudicar o patrão? O que eu já ouvi de história de você ficar com medo mesmo de comer por aí... Eu já soube de um cara que trabalhava numa lanchonete dessas grandes aí, e um dia tava chegando a hora de ir embora e um gerente desses puxa-saco da empresa resolveu que todo mundo ia fazer hora extra pra lavar o chão, arrumar estoque, essas coisas. Quando o gerente saiu, né, os funcionários já p. da vida com ele, fizeram um esquema: ficou um olhando se ele voltava, enquanto o outro abriu aqueles recipientes onde ficam os sucos, sabe? Esses refrescos? Ele abriu e urinou ali! É um idiota, acha que com isso vai prejudicar o patrão, mas quem vai se ferrar é ele! Além de botar muita gente em risco."

"Como é que pode, tem que demitir um imbecil desse, mandar prender! Que absurdo!"’. Karina mal pode se conter, mas André continua:

"E pior que essas coisas não são só pra ilustrar a aula não, isso acontece mesmo! Eu falo aqui e as pessoas acham que é mentirinha, historinha do André... É que tem gente muito tapada mesmo! Eu conheci um cara que simplesmente.... é, bom... como é que eu vou explicar... é... ele tava 'por aqui' com o dono da padaria, né, e, digamos... o cara depositou sua carga genética na massa."

É o estopim para uma série de reações indignadas e enojadas, apenas contidas pelo intervalo.

(Carriço, 2011: 32-33)

Existe, enfim, todo um humor marcadamente sexual que poderia muito bem ter sido relegado a diários de campo, a anedotas para compartilhar com amigos ou simplesmente esquecidos no momento que se passou, se não fosse fundamental para a compreensão de todo o processo de aprendizado de uma sensibilidade em relação à massa e a sua atividade como um todo.

\section{Algumas abordagens possíveis}

Trabalhar com esses pequenos gestos e acontecimentos que se revelam no dia-adia de um curso de qualificação possibilita ainda abordagens bastante produtivas de algumas questões chave para se compreender não só o tema do trabalho, mas do que se entende por economia em geral. Por exemplo, é possível pensar em operações matemáticas, noções de custo e lucro não como racionalidades fechadas, mas a partir de uma situação interessante onde se busca inculcar esse habitus, construí-las como indispensáveis e corretas. Como se ensina a calcular? Mais que fazer contas, está em jogo uma maneira de se conceber e se relacionar com os números, substâncias, e sua própria atividade. É, no limite, a busca da construção de um "homem econômico", em certo sentido, com inclinação ao investimento e à maximização das satisfações, que pode ser abordada de maneira interessante. 
Nesse sentido, podemos dialogar com Polanyi e pensar na questão do trabalho como mercadoria fictícia. O desenvolvimento de instituições especializadas no ensino recoloca a questão da produção efetiva do trabalhador, na medida em que existe todo um investimento específico para transformar pessoas em padeiros, em trabalhadores qualificados. Tal qual uma mercadoria "real", poderíamos pensar, o trabalhador seria então produzido para ser colocado no mercado de trabalho. Uma análise mais atenta, no entanto, revela as sutilezas que superam uma visão simplista dos processos em curso, uma vez que estes não podem ser dissociados da construção social de pessoas. Seria o trabalho, afinal, um fator dissociável da vida ou "apenas um outro nome para a atividade humana que acompanha a própria vida, que por sua vez, não é produzida para a venda mas por razões inteiramente diversas, e essa atividade não pode ser destacada do resto da vida, não pode ser armazenada ou mobilizada" (Polanyi, 2000: 94)?

Podemos seguir a retomada de autores clássicos do tema do trabalho pensando no postulado de Halbwachs (1972) segundo o qual o trabalhador se isola em sua relação com a matéria. Desta forma, há de se destacar o caráter extremamente transformador e mesmo subversivo que o espaço do curso lhe oferece, na medida em que esse afastamento das urgências do mundo, isto é, a formação de um profissional separada de seu ambiente de trabalho propriamente dito, faz das condições de trabalho e dos percalços do cotidiano na padaria fatores passíveis de apropriação e resignificação por parte daqueles que os enfrentam por meio de piadas, narrativas e troca de experiências. O padeiro, afinal, não é construído apenas com técnicas e manuais de panificação - esta é também uma categoria elaborada discursivamente.

Analisar o curso é deparar-se sobretudo com narrativas: histórias, anedotas e piadas que persistem da primeira aula de matemática ao último dia na oficina. Esta intensa prática dialógica marca o cotidiano da escola e faz do curso um contexto privilegiado de elaboração discursiva no qual alunos, professores e funcionários se constroem enquanto pessoas, enquanto trabalhadores, e reinventam a visão que têm de seu lugar no mundo.

Nesse espaço, certos assuntos se tornam temas interessantes para estruturar narrativas. A higiene ou a preocupação com o desperdício, por exemplo, que poderiam ser ignorados como questão em diversos outros contextos, tornam-se aqui o cerne de muitas das conversas. Não se trata exatamente das mesmas boas práticas de produção pregadas pelas diretrizes do sistema de ensino, no entanto. Embora sejam as preocupações institucionais as principais fontes geradoras de interesse em uma gama de 
temas, o caráter anedótico adotado pelas narrativas construídas reinventa tais questões, deslocando-as do aspecto extremamente sério que assumem nos regulamentos e discursos oficiais para imprimir-lhes um certo humor distintivo. É a partir dessa apropriação fundamental por meio da construção de narrativas nesse contexto privilegiado que o caráter transformador do curso se faz perceber.

Deste modo, conversar sobre experiências cotidianas tem implicações maiores que simplesmente proporcionar exemplos do trabalho de um padeiro para aprendizes do ofício, pois são justamente a elaboração e o compartilhamento de tais dispositivos narrativos que engendram um processo no qual os trabalhadores, mais que se submeter ao jugo de patrões ou do mercado, tornam-se capazes de apropriações criativas dessas relações. O resultado é a objetificação de todo um mundo do trabalho no qual a qualificação constitui um valor fundamental.

\section{Considerações finais: Como expandir o objeto sem negar as bases desse conhecimento?}

Há, enfim, inúmeras questões interessantes que podem ser desenvolvidas apenas nesse pequeno contexto de aulas ou do ensino. É evidente, no entanto, que este foco não esgota as possibilidades de pesquisa em relação a tudo o que envolve a formação profissional institucionalizada. Afinal, assumir uma abordagem etnográfica, por um lado, implica admitir, sim, certos "limites", sobretudo à amplitude dos "dados" "obtidos" - afinal, como "aluno", tive minha presença e possibilidade de tráfego e acessibilidade condicionados a uma pequena esfera em relação à Agência de Formação Profissional de Panificação e Confeitaria, ao SENAI da Tijuca, ao sistema SENAI como um todo, sem falar na situação da qualificação profissional no Rio de Janeiro ou no Brasil. Com mais tempo de pesquisa, provavelmente algumas dessas "falhas" seriam atenuadas. No entanto, quando assumimos de fato a etnografia não apenas como uma técnica para obter dados ou verificar hipóteses, mas em seu caráter essencialmente epistemológico, essas questões deixam de ser tão determinantes. Como "aluno", ainda que "aluno-antropólogo", tive minhas possibilidades limitadas, sim, mas foi justamente a partir dessa condição que todo o trabalho pôde ganhar corpo da maneira como se apresentou. Antes de se lamentar, é preciso reconhecer e saber explorar as condições criadas justamente por aquele pequeno contexto - não procurar sair ou expandi-lo o mais rápido possível, mas aprofundá-lo, investir no que se tem de modo que se possa trazer à tona toda a complexidade e densidade da menor das situações. É essa, a meu 
ver, a maior virtude e contribuição da antropologia, e é sobre essa ótica, creio, que se deve encarar uma pesquisa etnográfica.

Por outro lado, é evidente que uma compreensão mais profunda pede que se trabalhe com toda uma ampla rede - o SENAI é um enorme corpo burocrático que está longe de se restringir ao ambiente em que desenvolvi minha pesquisa, isto é, ao âmbito das relações entre alunos, conteúdos ministrados e professores. Pouco tive acesso ao cotidiano das secretárias, diretores e todo o corpo hierárquico do Sistema, por exemplo. Da mesma forma, as instâncias governamentais e acordos sindicais envolvidos apareciam em seu estado pronto, sem maiores aberturas, embora sua importância para o funcionamento do curso, e, portanto, para a análise, fosse indiscutível. Há ainda a passagem do aluno para o mercado de trabalho: como este profissional qualificado se relaciona com este estatuto, com seus colegas de profissão, patrões etc no dia a dia do trabalho propriamente dito? Saindo do curso, que dinâmicas essa relação potencialmente conflituosa engendra? Que possíveis transformações se associam à crença na qualificação como valor fundamental? Resta, enfim, uma série de questões que deverão ser exploradas em pesquisas futuras.

Se a abordagem etnográfica se mostrou muito produtiva em relação a todo o processo de aprendizado de técnicas e valores relativos à panificação, até por permitir senti-lo no próprio corpo, ela impõe um desafio no momento em que se procura expandir o objeto da pesquisa. A atenção ao quadro burocrático e às tomadas de decisões, bem como ao cotidiano do trabalho, não se opõe, de certo, ao foco assumido pela dissertação. Pelo contrário, estudar o que se poderia chamar provisória e precipitadamente de condicionantes externos ao ensino certamente mostrar-se-á fundamental para que se observe como estas questões se relacionam com o ambiente da aula, tanto as "teóricas" quanto as "práticas".

A questão que se impõe é na maneira como essa passagem deve ser trabalhada: como fazer estas pontes entre o que pude apreender em sala de aula e todo um leque de possibilidades que se apresenta sem que as particularidades - e as maiores virtudes - do conhecimento construído sejam negadas ou subestimadas em nome de ambições megalomaníacas?

Abordar um sistema altamente burocratizado e espalhado pelo Brasil, destinado aos mais diversos setores da indústria, é sem dúvida uma empreitada que apresenta dificuldades a um etnógrafo. Seria preciso, de início, repensar minha relação com professores e funcionários para negociar uma nova inserção, já que o lugar restrito do 
aluno se mostrou insuficiente para lidar com estas temáticas. Ao mesmo tempo, inserido menos "organicamente" em seu campo, o pesquisador pode deparar-se novamente com a dificuldade de conciliar os ritmos do trabalho e os da pesquisa, como pude experimentar em investidas posteriores a campo.

A questão relativa ao acesso ao campo não possui, enfim, uma resposta ideal. Pelo contrário, é uma reflexão fundamental da antropologia sobre o necessário e constante trabalho de negociação da situação em que o pesquisador se insere, por um lado, mas que ele mesmo provoca através da pesquisa (Gellner \& Hirsch, 2001). Novamente, é preciso compreender e saber explorar o lugar que construímos na relação com as pessoas que estudamos. Não apenas para que se explicite o ponto de partida do pesquisador, mas porque o próprio trabalho de manutenção da relação com as pessoas envolvidas é extremamente fértil e revelador. Apenas assim as dificuldades de acesso poderão ser encaradas em seu lado positivo para a pesquisa, o de revelar traços e lógicas sociais que talvez sequer fossem notadas de outra maneira.

\section{Referências}

BOURDIEU, Pierre. Meditações pascalianas; tradução Sergio Miceli. Rio de Janeiro: Bertrand Brasil, 2001.

CARRIÇO, Antônio de Salvo. Segredos de Profissão: notas etnográficas de um aprendiz de padeiro. Dissertação (Mestrado em Antropologia Social). Museu Nacional/PPGAS, Universidade Federal do Rio de Janeiro. Rio de Janeiro: UFRJ, 2011. FAVRET-SAADA, J. "Être affecté. Gradhiva". In: Revue d'Histoire et d'Archives de l'Anthropologie, 8. Paris: Département d'Archives de l'Ethnologie du Musée de l'Homme, 1990. p 3-9.

GELLNER, David N. \& HIRSCH, Eric, eds. -Inside Organizations: Anthropologists at Work. Oxford: Berg Publishers, 2001.

GUEDES, Simoni. Jogo de corpo: Um estudo de construção social de trabalhadores. Niterói, Rio de Janeiro: EDUFF, 1997.

HALBWACHS, Maurice. Classes sociales et morphologie. Paris: Minuit, 1972.

MOYSÉS, Brejon. Recursos humanos, ensino técnico e desenvolvimento: uma perspectiva brasileira. São Paulo: Pioneira, 1968.

POLANYI, Karl. A Grande Transformação: as origens da nossa época. Rio de Janeiro: Campus, 2000.

POWDERMAKER, Hortense. Stranger and friend; the way of an anthropologist. New York: W. W. Norton \& Company, 1966.

STOCKING Jr., G. "The ethnographer's magic: fieldwork in British anthropology from Tylor to Malinowski”. In: STOCKING Jr, G. (ed.) Observers observed: essays on ethnographic fieldwork, v. 1. Madison: The University of Wisconsin Press, 1983. p. 70120. 
WEBER, Florence. Trabalho fora do trabalho: uma etnografia das percepções. Rio de Janeiro: Garamond, 2009.

Recebido em: 29/04/2012

Aprovado em: 29/06/2012 